\title{
Should We Assess Diaphragmatic Function During Mechanical Ventilation Weaning in Guillain-Barré Syndrome and Myasthenia Gravis Patients?
}

\author{
Nicolas Weiss ${ }^{1,2,3^{*}}$ (1)
}

(C) 2021 Springer Science+Business Media, LLC, part of Springer Nature and Neurocritical Care Society

Acute respiratory failure is the main reason for the admission of Guillain-Barré syndrome (GBS) and myasthenia gravis (MG) patients to the ICU. About $30 \%$ of GBS patients and 10 to $30 \%$ of MG patients will require mechanical ventilation (MV) over their disease course [1-3]. Once the disease and eventually its triggering event are treated, time for weaning begins. Liberation from MV, i.e. extubation success, constitutes the final achievement of this process. Outside the scope of neurocritical care unit (NICU), patients are now sorted into four weaning groups [4] (Table 1): the group "no weaning", made of patients who never experienced any separation attempt; the group 1 (short weaning): the first attempt resulted in a termination of the weaning process within 1 day; the group 2 (difficult weaning): the weaning was completed after more than 1 day but in less than 1 week after the first separation attempt and the group 3 (prolonged weaning): weaning was still not terminated 7 days after the first separation attempt. Even if the original study including 2729 patients did not excluded specifically GBS or MG patients, their proportion was likely to be limited and no study have used this classification in these patients. However, between 26 [5] and 75\% [6] of GBS or MG patients are still under MV at day 7 and

\footnotetext{
${ }^{*}$ Correspondence: nicolas.weiss@aphp.fr

${ }^{1}$ Sorbonne University \& Neurological Intensive Care Unit, Department of Neurology, AP-HP.Sorbonne Université, Hôpital Pitié-Salpêtrière, 47-83, Boulevard de l'Hôpital, 75013 Paris, France

Full list of author information is available at the end of the article
}

This comment refers to the article available at https://doi.org/10.1007/ s12028-020-01141-9. most authors assume that extubation failure accounts for $30 \%$ in those patients [5, 7]. Whereas prolonged MV is associated with an increased risk of ventilator-associated pneumonia, premature liberation is associated with increased risk of extubation failure and increased risk of mortality and morbidity $[5,8]$. Hence, determining the optimal timing for extubation is of major importance.

Several questions arise when the weaning process begins: (1) which ventilation mode should be preferred to enable the respiratory muscles to both rest and not to waste? [9]; (2) when to start spontaneous breathing trials (SBT)?; (3) should positive pressure support (PSV) or T-piece trials be used for SBT?; (4) which respiratory parameters should be used to predict successful extubation?; and finally (5) is there any place for non-invasive mechanical ventilation (NIV) or high-flow nasal oxygenation to increase extubation success rate?

Synchronized intermittent mandatory ventilation is now discouraged since this mode was associated with prolonged weaning $[8,10]$, and pressure support ventilation (PSV) should be preferred over assisted ventilation when weaning begins $[8,11,12]$. In general ICU, readiness criteria to start SBT and readiness criteria for extubation are widely accepted and should probably at least be applied to NICU patients (Table 1) [8, 11]. In GBS and MG patients, forced vital capacity and maximal inspiratory pressure are frequently added to these minimal criteria (Table 1) [5]. Whereas no difference has been found in SBT duration when ranging from $30 \mathrm{~min}$ to $2 \mathrm{~h}$ in general ICU [8], most neurointensivists performed "prolonged" SBT in GBS and MG patients going from one to several hours, up to $12-24 \mathrm{~h}$, but this practice is 
Table 1 Weaning according to a new definition (WIND) classification and criteria for considering a spontaneous breathing trial (SBT) in general ICU and in neurocritical ICU

Weaning according to a new definition (WIND) classification

Group "no weaning": made of patients who never experienced any separation attempt

Group 1 (short weaning): the first attempt resulted in a termination of the weaning process within 1 day (successful separation or early death)

Group 2 (difficult weaning): the weaning was completed after more than 1 day but in less than 1 week after the first separation attempt (successful separation or death)

Group 3 (prolonged weaning): the weaning was still not terminated 7 days after the first separation attempt (by successful separation or death)

Group 3a prolonged weaning leading to a successful weaning after 7 days or more after the first attempt

Group 3b prolonged weaning without success

\section{Criteria for considering SBT}

General ICU

Resolution of the medical condition that led to MV

Hemodynamic stability (BPM $<135 / \mathrm{min}, 90<$ systolic arterial pressure $<160 \mathrm{mmHg}$ with no need for vasopressors)

Patient awake or easily aroused (RASS between 1 and -2 ) and sedation stopped

Patient able to cough effectively

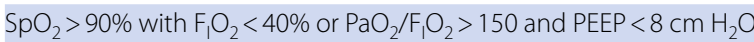

$\mathrm{RR}<35 / \mathrm{min}$

$\mathrm{pH}>7.35$

Neurocritical ICU, especially GBS and MG patients

Resolution of the medical condition that led to MV

Hemodynamic stability (BPM $<135 / \mathrm{min}, 90<$ systolic arterial pressure $<160 \mathrm{mmHg}$ with no need for vasopressors)

Patient awake or easily aroused (RASS between 1 and -2 ) and sedation stopped

Patient able to cough effectively

Adequate secretion clearance (cough strength)

$\mathrm{SpO}_{2}>90 \%$ with $\mathrm{FIO}_{2}<40 \%$ or $\mathrm{PaO}_{2} / \mathrm{FIO}_{2}>150$ and $\mathrm{PEEP}<8 \mathrm{~cm} \mathrm{H}_{2} \mathrm{O}$

$\mathrm{RR}<35 / \mathrm{min}$

$\mathrm{pH}>7.35$

Normal blood gases

Forced vital capacity (FVC) $>10 \mathrm{~mL} / \mathrm{kg}$ (or 15 or improvement of more than $4 \mathrm{~mL} / \mathrm{kg}$ )

Maximal inspiratory pressure $>-20 \mathrm{~cm} \mathrm{H} 20$

Maximal expiratory pressure $>40 \mathrm{~cm} \mathrm{H} 2 \mathrm{O}$

$B P M$ beats per minute, $F V C$ forced vital capacity, $\mathrm{F}_{1} \mathrm{O}_{2}$ inspired oxygen fraction, $G B S$ Guillain-Barré syndrome, $M G$ myasthenia gravis, $M V$ mechanical ventilation, $\mathrm{PaO}_{2}$ partial oxygen arterial pressure, PEEP positive end-expiratory pressure, PSV pressure support ventilation, RASS Richmond assessment sedation scale, $R R$ respiratory rate, $S B T$ spontaneous breathing trial, $\mathrm{SpO}_{2}$ pulsed oxygen saturation

performed without supportive data [6,13]. It has recently been shown that the use of PSV could be associated with an earlier liberation of MV compared to T-piece trials in intubated patients in general ICU [14], whereas these latter's could be preferred in patients with tracheotomy $[8$, 12].

Extubation success is classically predicted by clinical parameters at the end of the SBT, by blood gases if clinical parameters fail. In neuromuscular patients, they are of limited interest since inconsistent results have been found [5, 12, 15-17]. Some authors proposed to assess diaphragmatic performance in these patients and found that an increase in maximal transdiaphragmatic pressure was predictive of weaning success and was superior to inspiratory pressure [18]. Unfortunately, the technique used was not easily applicable in every patient. It should be noticed that in MG patients, residual bulbar weakness can be revealed in some cases only after extubation. This probably explains failure of these parameters to predict successful extubation. Limited data are available on strategies to increase success rate after extubation in GBS or MG patients. Rabinstein et al. presented however encouraging results for NIV after extubation in MG patients [19]. These strategies should be precised in neuromuscular patients, since in general ICU NIV have been proven to be effective if $\mathrm{P}_{\mathrm{a}} \mathrm{CO}_{2}$ where higher then $45 \mathrm{mmHg}$ and high-flow 
nasal oxygen associated to NIV was superior to highflow nasal oxygen alone to prevent extubation failure [20].

In this issue of the journal, Krishnakumar et al. present original data on a dynamic evaluation of diaphragm function assessment during SBT in patients with neuromuscular diseases. This work suggests that new available tools could be valuable in these patients. Weaning failure is due to the imbalance between the mechanical load imposed on the diaphragm and the capacity of the respiratory system to cope with it. Based on that, the authors evaluated prospectively diaphragm functioning during SBT using diaphragm ultrasonography and diaphragm electrical activity (Edi peaks using neurally adjusted ventilatory assist (NAVA) catheter) every $30 \mathrm{~min}$. Indeed, diaphragmatic thickening fraction (DTF) correlates with the diaphragm workload and electrical activity of the diaphragm (Edi) is a surrogate of respiratory drive. Eight patients with neuromuscular diseases (five GBS and three MG patients) on MV for more than 7 days could be evaluated. Their preliminary results suggest that over time as patients progress towards successful weaning Edi values and DTF stabilize over the SBT. Interestingly, neither respiratory rate nor End-tidal $\mathrm{CO}_{2}\left(\mathrm{EtCO}_{2}\right)$ did change over the weaning period. In the general ICU population, a recent study found that neither changes in DTF nor in diaphragmatic excursion was associated to extubation failure [21, 22]. Concerning Edi, a study performed in a NICU population including stroke and traumatic brain injury patients showed that an increase in Edi by $12 \%$ reflected patient exhaustion [23]. Concerning MG, a single-case report suggested its usefulness as an early marker of respiratory muscles recovery [24]. Some limitation should however be emphasized. A major limitation is the huge interindividual Edi variations [25] that explains that some authors proposed to use instead Edi/ tidal volume ratio $[26,27]$. The sample size was very limited, and it is not sure that GBS and MG behave exactly the same way. Thus, further studies should probably focus on a larger and more homogenous population. Edi values reported here were clearly lower than classically described. Is this as proposed by the authors solely due to the chronic muscle waste possibly present in this specific population? if this hypothesis could be easily proposed in MG, it is less evident in the acute setting of GBS. Another limitation is the feasibility of the ultrasonography of the diaphragm and the other extradiaphragmatic respiratory muscles $[28,29]$. Patients with poor ultrasound window for diaphragm assessment were here excluded. Nevertheless, diaphragm ultrasonography is non-invasive and feasible at bedside in every NICU. Whereas Edi catheter placement is very close to the placement of a nasogastric tube, those catheters are not nowadays widely used.
To conclude, this paper addresses weaning strategies of patients with neuromuscular diseases, which is a major issue in NICU. It originally proposes to use dynamically new tools available at bedside to identify early diaphragmatic exhaustion and prevent SBT failure and its consequences. Nevertheless, the lack of consensus on the categorization of weaning groups and the absence of any uniform definition of extubation failure in neuromuscular patients preclude the improvement in weaning strategies in these patients. Bedside available tools are only half of the problem.

We would like to thank Dr Martin Dres, MD, PhD, and Dr Loï Le Guennec, $M D, P h D$, for their critical review of the manuscript.

\section{Author details \\ ${ }^{1}$ Sorbonne University \& Neurological Intensive Care Unit, Department of Neurology, AP-HP.Sorbonne Université, Hôpital Pitié-Salpêtrière, 47-83, Boulevard de l'Hôpital, 75013 Paris, France. ${ }^{2}$ Groupe de Recherche Clinique en REanimation et Soins intensifs du Patient en Insuffisance Respiratoire aiguE (GRC-RESPIRE), Sorbonne Université, Paris, France. ${ }^{3}$ Brain Liver Pitié-Salpêtrière (BLIPS) Study Group, Sorbonne Université, INSERM UMR_S 938, Centre de Recherche Saint-Antoine, Maladies Métaboliques, Biliaires et Fibro-Inflamma- toire du Foie, Institute of Cardiometabolism and Nutrition (ICAN), Paris, France.}

\section{Conflicts of Interest}

Dr Nicolas Weiss received consultant fees from MedDay pharmaceuticals.

\section{Publisher's Note}

Springer Nature remains neutral with regard to jurisdictional claims in published maps and institutional affiliations.

Received: 15 November 2020 Accepted: 18 November 2020 Published online: 9 January 2021

\section{References}

1. Yuki N, Hartung H-P. Guillain-Barré syndrome. N Engl J Med. 2012;366:2294-304. https://doi.org/10.1056/NEJMra1114525.

2. Desforges JF, Ropper AH. The Guillain-Barré syndrome. N Engl J Med. 1992;326:1130-6. https://doi.org/10.1056/NEJM199204233261706.

3. Oosterhuis HJ. Observations of the natural history of myasthenia gravis and the effect of thymectomy. Ann NY Acad Sci. 1981;377:678-90. https //doi.org/10.1111/j.1749-6632.1981.tb33766.x

4. Béduneau G, Pham T, Schortgen F, et al. Epidemiology of weaning outcome according to a new definition. the WIND study. Am J Respir Crit Care Med. 2017;195:772-83. https://doi.org/10.1164/rccm.201602-03200 C.

5. Seneviratne J, Mandrekar J, Wijdicks EFM, Rabinstein AA. Predictors of extubation failure in myasthenic crisis. Arch Neurol. 2008. https://doi. org/10.1001/archneur.65.7.929.

6. Thomas CE, Mayer SA, Gungor Y, et al. Myasthenic crisis: clinical features, mortality, complications, and risk factors for prolonged intubation. Neurology. 1997;48:1253-60. https://doi.org/10.1212/WNL.48.5.1253.

7. Varelas PN, Chua HC, Natterman J, et al. Ventilatory care in myasthenia gravis crisis: assessing the baseline adverse event rate* Crit Care Med. 2002;30:2663-8. https://doi.org/10.1097/00003246-200212000-00009.

8. Brochard L, Thille AW. What is the proper approach to liberating the weak from mechanical ventilation? Crit Care Med. 2009;37:S410-5. https://doi. org/10.1097/CCM.0b013e3181b6e28b.

9. Goligher EC, Brochard LJ, Reid WD, et al. Diaphragmatic myotrauma: a mediator of prolonged ventilation and poor patient outcomes in 
acute respiratory failure. Lancet Respir Med. 2019;7:90-8. https://doi. org/10.1016/S2213-2600(18)30366-7.

10. Esteban A, Frutos F, Tobin MJ, et al. A comparison of four methods of weaning patients from mechanical ventilation. N Engl J Med. 1995;332:345-50. https://doi.org/10.1056/NEJM199502093320601.

11. Jung $B$, Vaschetto $R$, Jaber $S$. Ten tips to optimize weaning and extubation success in the critically ill. Intensive Care Med. 2020. https://doi. org/10.1007/s00134-020-06300-2.

12. Rabinstein AA, Mueller-Kronast N. Risk of extubation failure in patients with myasthenic crisis. Neurocrit Care. 2005;3:213-5. https://doi. org/10.1385/NCC:3:3:213.

13. Ropper AH, Kehne SM. Guillain-Barre syndrome: management of respiratory failure. Neurology. 1985;35:1662. https://doi.org/10.1212/ WNL.35.11.1662.

14. Thille AW, Coudroy R, Nay M-A, et al. Pressure-support ventilation vs T-piece during spontaneous breathing trials before extubation among patients at high risk of extubation failure. Chest. 2020;158:1446-55. https ://doi.org/10.1016/j.chest.2020.04.053.

15. Wu J-Y, Kuo P-H, Fan P-C, et al. The role of non-invasive ventilation and factors predicting extubation outcome in myasthenic crisis. Neurocrit Care. 2009;10:35-42. https://doi.org/10.1007/s12028-008-9139-y.

16. Tanios MA, Nevins ML, Hendra KP, et al. A randomized, controlled trial of the role of weaning predictors in clinical decision making*. Crit Care Med. 2006:34:2530-5. https://doi.org/10.1097/01.CCM.0000236546.98861.25.

17. Ko R, Ramos L, Chalela JA. Conventional weaning parameters do not predict extubation failure in neurocritical care patients. Neurocrit Care. 2009:10:269-73. https://doi.org/10.1007/s12028-008-9181-9.

18. Borel CO, Tilford C, Nichols DG, et al. Diaphragmatic performance during recovery from acute ventilatory failure in Guillain-Barré syndrome and myasthenia gravis. Chest. 1991;99:444-51. https://doi.org/10.1378/chest 99.2.444.

19. Rabinstein AA, Wijdicks EFM. Weaning from the ventilator using bipap in myasthenia gravis. Muscle Nerve. 2003;27:252-3. https://doi.org/10.1002/ mus.10329.

20. Thille AW, Muller G, Gacouin A, et al. Effect of postextubation high-flow nasal oxygen with noninvasive ventilation vs high-flow nasal oxygen alone on reintubation among patients at high risk of extubation failure: a randomized clinical trial. JAMA. 2019;322:1465. https://doi.org/10.1001/ jama.2019.14901.

21. DiNino E, Gartman EJ, Sethi JM, McCool FD. Diaphragm ultrasound as a predictor of successful extubation from mechanical ventilation. Thorax. 2014;69:431-5. https://doi.org/10.1136/thoraxjnl-2013-204111.

22. Vivier E, Muller M, Putegnat J-B, et al. Inability of diaphragm ultrasound to predict extubation failure. Chest. 2019;155:1131-9. https://doi. org/10.1016/j.chest.2019.03.004

23. Trapp O, Fiedler M, Hartwich M, et al. Monitoring of electrical activity of the diaphragm shows failure of T-piece trial earlier than protocol-based parameters in prolonged weaning in non-communicative neurological patients. Neurocrit Care. 2017;27:35-43. https://doi.org/10.1007/s1202 8-016-0360-9.

24. Koyama Y, Yoshida T, Uchiyama A, Fujino Y. Monitoring diaphragm function in a patient with myasthenia gravis: electrical activity of the diaphragm vs. maximal inspiratory pressure. J Intensive Care. 2017;5:66. https://doi.org/10.1186/s40560-017-0262-8.

25. Dres M, Demoule A. Monitoring diaphragm function in the ICU. Curr Opin Crit Care. 2020;26:18-25. https://doi.org/10.1097/MCC.0000000000000068 2.

26. Barwing J, Pedroni C, Olgemöller U, et al. Electrical activity of the diaphragm (EAdi) as a monitoring parameter in difficult weaning from respirator: a pilot study. Crit Care. 2013;17:R182. https://doi.org/10.1186/ cc12865.

27. Rozé H, Repusseau B, Perrier V, et al. Neuro-ventilatory efficiency during weaning from mechanical ventilation using neurally adjusted ventilatory assist. Br J Anaesth. 2013;111:955-60. https://doi.org/10.1093/bja/aet258.

28. Dres M, Dubé B-P, Goligher E, et al. Usefulness of parasternal intercostal muscle ultrasound during weaning from mechanical ventilation. Anesthesiology. 2020;132:1114-25. https://doi.org/10.1097/ALN.0000000000 003191.

29. Tuinman PR, Jonkman AH, Dres M, et al. Respiratory muscle ultrasonography: methodology, basic and advanced principles and clinical applications in ICU and ED patients - a narrative review. Intensive Care Med. 2020;46:594-605. https://doi.org/10.1007/s00134-019-05892-8. 